\title{
HAEMOSTATIC AND ANTIMICROBIAL EFFECTS OF A HERBAL AGENT VERSUS PLATELET RICH PLASMA ON THE MANAGEMENT OF OROANTRAL FISTULA THROUGH CALDWELL-LUC APPROACH
}

\author{
Mohamed Shokry* and Marwa Gamaleldin Noureldin**
}

\begin{abstract}
The purpose of this study is to compare the use of a herbal haemostatic agent to Platelet Rich Plasma (PRP) in the maxillary sinus after the Caldwell-Luc surgery for the closure of the OroAntral Fistula (OAF).

This study included 20 adult patients, who had an OAF that was treated using the CaldwellLuc method. They were divided randomly into two groups: Group A: Surgicel soaked with herbal haemostatic agent was packed in the sinus prior to close the OAF. Group B: Surgicel soaked in PRP was packed in the sinus before closing the OAF. Clinical evaluations were performed at different intervals to assess postoperative pain, oedema, bleeding, and infection. Microbiological assessment was accomplished by comparing a swab taken intraoperatively from the maxillary sinus to a swab taken one week later from the pharyngeal posterior wall (post nasal discharge). After three months, a radiographic evaluation utilising $\mathrm{CBCT}$ was performed to assess the fluid level in the affected maxillary sinus.
\end{abstract}

The herbal haemostatic drug and PRP showed similar results in terms of pain, oedema, bleeding, and infection. Also, both groups were effective in decreasing the fluid level buildup. Conversely, the microbiological tests showed that bacterial growth declined more with the herbal agent than with the PRP.

As a conclusion, there were little postoperative complications with the herbal haemostatic medication and PRP. Both were also successful in lowering the amount of fluid in the maxillary sinus. The herbal haemostatic medication, on the other hand, surpassed PRP in terms of antibacterial activity.

* Associate Professor of Oral and Maxillofacial Surgery, Faculty of Dentistry, Alexandria University, Egypt.

** Lecturer of Oral and Maxillofacial Surgery, Faculty of Dentistry, Alexandria University, Egypt. 


\section{INTRODUCTION}

Since the maxillary sinus is connected to the oral, nasal cavity, and the ear, it is considered as one of the most significant structures in the oral and maxillofacial region. Consequently, the maxillary sinus can be affected by a variety of issues and diseases, which can arise from either oral or nasal sources. ${ }^{(1)}$

Maxillary sinusitis, which can be acute, subacute, or chronic, is the most prevalent condition affecting the maxillary sinus. Facial pain or pressure, especially when the head is turned down, purulent nasal discharge, nasal blockage, and a diminished or absent sense of smell are all symptoms of sinusitis. ${ }^{(2)}$

Oroantral fistula (OAF) is a pathological communication between the oral cavity epithelium and the maxillary sinus that can develop as a result of iatrogenic problems, dental infections, osteomylitis, trauma, radiation therapy, or after implant installation. ${ }^{(3)}$

Caldwell-Luc technique is a surgical intervention used in the treatment of chronic maxillary sinusitis, which involves the removal of granulation tissue and curettage of the sinus cavity. ${ }^{(4)}$ The CaldwellLuc method is used to access the maxillary sinus in order to drain pus or avoiding it's accumulation in the sinus by placing a surgical pack, followed by a nasal antrostomy. This nasal pack has a number of drawbacks, including blood collection in the sinuses and nasal bleeding, as well as being extremely painful to remove. It acts as a foreign body after surgery, causing infection and obstructive sleep apnea. ${ }^{(5)}$

Herbal drugs made from plant extracts that functions as hemostatic and antibacterial agents have been included in the prevention and treatment of excessive haemorrhage caused by dental treatments. ${ }^{(6)}$

Platelet-Rich Plasma involves a large number of platelets in a minor fraction of plasma ${ }^{(7)}$. This product replicates the final step of the coagulation cascade, resulting in the production of a fibrin clot that quickly consolidates and adheres to the application site. PRP has hemostatic and healing characteristics which can retain tissues in a certain position. ${ }^{(8)}$

Therefore, this study aimed to compare between the use of a herbal haemostatic agent and PlateletRich Plasma (PRP) in the maxillary sinus after Caldwell-Luc surgery for the closure of the (OAF).

\section{MATERIALS AND METHODS}

\section{Study design}

This study was carried out as randomized blinded comparative clinical trial. The sample size was calculated by using the epitools.auvset.com.au sample size calculation website. Randomization of the sample was performed by randomizer.org website. The allocation concealment was done through closed envelopes that include the number of the patients selected to participate in this study. Therefore, twenty patients with an established OroAntral Fistula (OAF) who required to be treated with the Caldwell-Luc operation were chosen from an outpatient clinic at the Faculty of Dentistry's Oral and Maxillofacial Surgery Department- Alexandria University.

All the patients have been informed in details about the whole procedure and asked to sign a written informed consent for the participation in this clinical trial. This trial has been approved from the ethics committee of the Faculty of DentistryAlexandria University.

\section{Sample size calculation}

The sample size was calculated using a 5\% alpha error and an 80 percent study power. A minimum sample size of 9 patients per group was calculated. This was extended to 10 patients per group to compensate for cases that failed to follow-up. Total 
sample $=$ number of patients in each group multiplied by the number of groups $=10 \times 2=20$ patients. The sample size was based on Rosner's method (9) and was calculated by Gpower 3.0.10 software. (10)

Inclusion criteria included non-smoker patients with good oral hygiene, either male or females, with age range between 20-50 years old suffering from a well-established OAF $>5 \mathrm{~mm}$ diameter need to be managed through aCaldwell-Luc approach.Excluding patients with malignancy, patients suffering from chronic bilateral maxillary sinus disease, pregnant or lactating female and patients with any systemic disorders contraindicating general anesthesia.

The patients were divided randomly into two groups:

Group A: Surgicel soaked in herbal haemostatic agent was packed in the diseased sinus prior to closure of the oro-antral fistula with buccal advanced flap and/or palatal pedicle flap through CaldwellLuc approach

Group B: Surgicel soaked in PRP was inserted within the affected sinus to close the oro-antral fistula with buccal advanced flap and/or palatal pedicle flap through Caldwell-Luc approach.

\section{Materials}

\section{A) Herbal Hemostatic agent}

It is a pure herbal ampoule (Fig. 1) (Ankaferd Blood Stopper ImmunGidaIlacKozmetik San.ve Tic. Ltd. Sti.Kirecburnu Cad. Raifbey Sk. No:8/A Kirecburnu Sariyer, Istanbul - Turkiye.) It is composed of mixture of plants Thymus vulgaris, Glycyrrhizaglabra, Vitisvinifera, Alpiniaoffcinarum and Urticadioica. It acts by forming encapsulated protein network offering focal points for erythrocyte aggregation. Also it has an antimicrobial action against Gram positive and Gram negative, acting as antibacterial agent against Streptococcus pyogenes, Staphylococcus aureus and Staphylococcus epidermidis. ${ }^{(6,11)}$

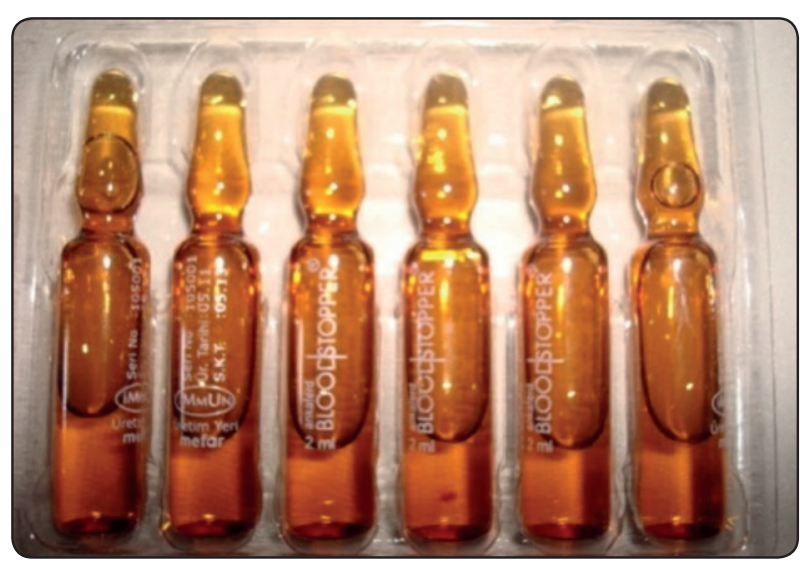

Fig. (1) Ampoules of herbal blood stopper agent

\section{B) Platelet Rich Plasma (PRP)}

Approximately $9 \mathrm{~mL}$ of venous blood was be collected from the patients then transferred into 10 $\mathrm{ml}$ syringe. The PRP protocol used a double spin centrifugation process. A millilitre of anticoagulant dextrose solution was added to the mixture. The finger-holders of two disposable $5 \mathrm{ml}$ syringes were cut with scissors. Each syringe received four millilitres of whole blood. The first centrifugation step was completed at 3,500 rpm for 3 minutes. After isolation of the plasma from red blood cells, an extension tube was used to aspirate plasma and transfer it to another syringe. The second spin step was performed at 4,000 rpm for 15 minutes. The resultant plasma was divided into platelet poor plasma (PPP) in the top 2/3 and platelet rich plasma PRP in the lower third. Finally, the PPP was discarded and about 2-4 $\mathrm{mL}$ of pure PRP was acquired. ${ }^{(12)}$

\section{C) Surgicel}

It is sterile and absorbable haemostatic agent (membrane by Johnson \& Johnson's Earthwards) used to control bleeding in oral surgery. It is produced from oxidized regenerated cellulose and it is fully absorbable within 7-14 days. It was used as a carrier for the application of Herbal Hemostatic agent and the PRP. 


\section{Methods}

\section{A) Preoperative phase}

History taking and clinical examination were proceeded for all patients. The presence of pus secretion, polyp extrusion, regurgitation of liquids from mouth into nose, and inability to blow out cheeks were all used to confirm the presence of an established OAF that needed to be treated with a buccal advanced flap and/or palatal pedicle flap through the CaldwellLuc approach.

In addition, a CBCT radiographic examination (Fig. 2a, 3a) was performed to identify the amount of fluid in the maxillary sinus, the extent of the oro-antral fistula, and the presence of a lesion when compared to the normal contralateral side.

\section{B) Operative phase}

In the operating theatre of the Oral and Maxillofacial Surgery Department, Faculty of Dentistry, Alexandria University. All surgeries were performed under general anaesthesia and the surgical field was disinfected with betadine.

The OAF was decored and a mucoperiosteal incision was made using bard- parker scalpel blade number 15 from the incisors to the upper molar region. The flap was then reflected to gain access to the sinus via the Caldwell-Luc approach, which involved bone removal at the upper premolars region. (Fig. 2b, 3b)

A swab of maxillary sinus fluid was collected (Fig. 2c) to determine the kind of bacteria using culture media. Curettage, maxillary sinus lining removal, and removal of foreign material if present. Surgicel ${ }^{\circledR}$ soaked in the herbal hemostatic agent (Fig. 2d,2e) was placed in the maxillary sinus in the group A. On the other hand, surgicel soaked with PRP (Fig. 3c, 3d) was placed in the maxillary sinus in the group $B$. The OAF was closed with a buccal advancement flap and sutured with mattress and interrupted $3 / 0$ black silk sutures. (Fig. 2f, 3e)

\section{C) Postoperative phase and instructions}

After recovery from the general anesthesia, the patients were instructed to keep biting on the pack for 2 hours, apply extraoral cold fomentation on the side of surgery at interval of $15 \mathrm{~min} /$ hour for $24 \mathrm{hr}$. Also, they were asked to avoid any mouth wash and any hot drinks or food for $24 \mathrm{hr}$. Any negative or positive pressure as smoking, blowing, sucking and coughing were prohibited. Sutures were removed after one week.

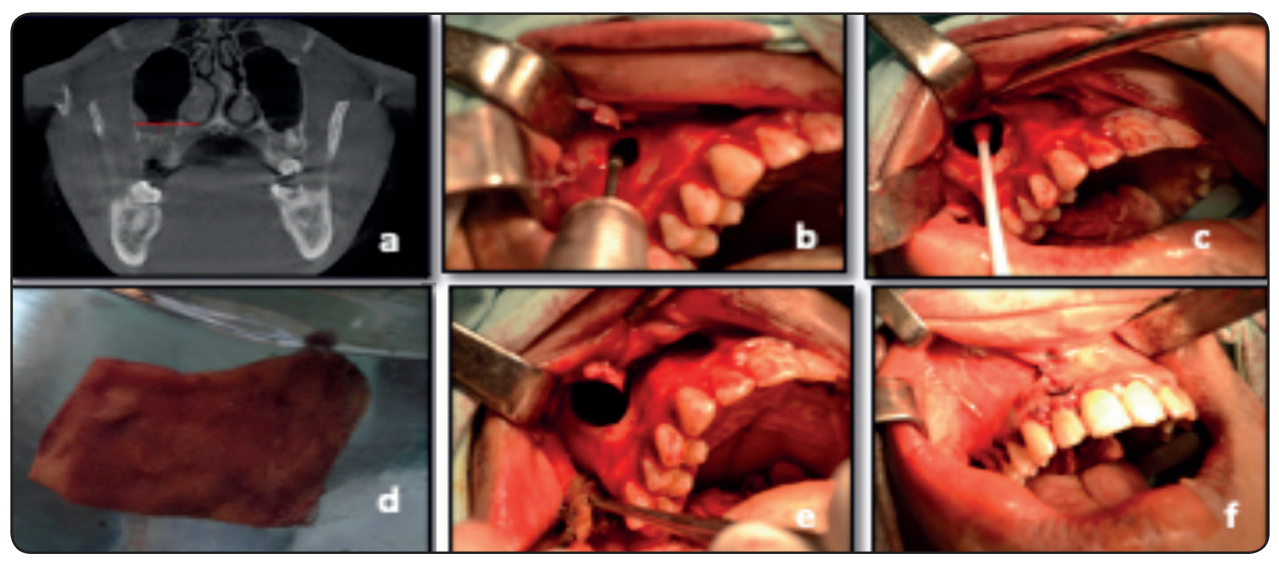

Fig. (2): a: Preoperative coronal view of CBCT showing fluid level in the Rt maxillary sinus and OAF. b: Full thickness flap reflection and access to the sinus by Caldwell-Luc approach. c: Swab collection from the maxillary sinus fluid. d: Surgicel soaked in the herbal haemostatic agent (Group A). e: Packing of the soaked surgicel in the sinus after its debridement. f: Closure of the flap by interrupted $3 / 0$ silk suture. 


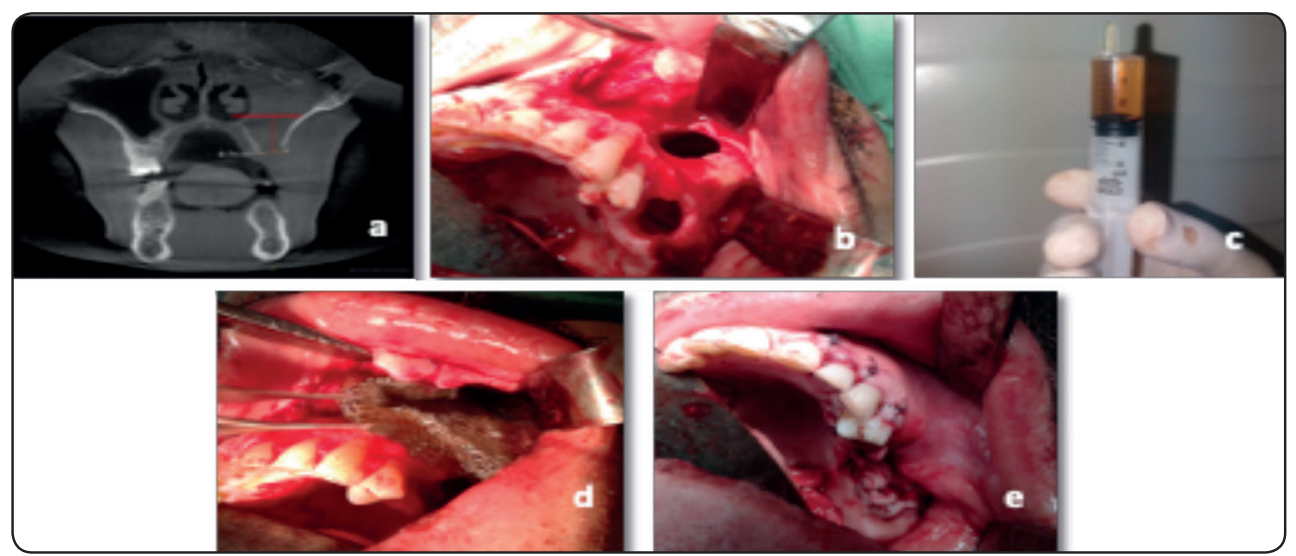

Fig. (3): a: Preoperative coronal view of CBCT showing huge amount of fluid level in the Lt maxillary sinus and OAF. b: Full thickness flap reflection and access to the sinus by Caldwell-Luc approach \& decoring of a large OAF. c: Plastic syringe with PRP ready to be applied on the surgicel. d: Packing of the soaked surgicel with PRP in the sinus after its debridement. (Group B) e: Closure of the buccal advancement flap by interrupted and mattress 3/0 silk suture.

\section{D) Follow-up evaluation}

\section{Clinical evaluation}

Clinical evaluations were performed immediate postoperatively, at three days, one week later, two weeks later, one month, and three months after surgery to assess postoperative pain, oedema, bleeding, and infection.

Postoperative pain was assessed using the visual analog scale. Percentage of facial swelling after surgery was evaluated using a flexible ruler to measure the distance from the corner of the mouth to the tip of the tragus (horizontal measurement) and the distance from the outer canthus of the eye to the angle of the jaw (vertical measurement). The mean of facial swelling was calculated by dividing the horizontal and vertical measurements by two. ${ }^{(13)}$

Facial Swelling Percentage $=$

$\underline{\text { Postopr. measurement }- \text { Preopr. measurement }}=\mathrm{x} 100$ Preopr. measurement

Postoperative bleeding was determined by the presence or absence of blood in the nostrils. Possibility of postoperative infection was based on the presence or absence of pus.

\section{Microbiological evaluation}

Microbiological assessment was accomplished by comparing a swab taken intraoperatively from the maxillary sinus to a swab taken one week later from the pharyngeal posterior wall (post nasal discharge). (14)

\section{Radiographic evaluation}

Radiographic evaluation after three months, utilizing CBCT was performed to assess the fluid level in the afflicted maxillary sinus.This was accomplished on the coronal view at the site of the oro-antral fistula by drawing a line from the inferior turbinate to the lateral surface of the maxillary sinus and dissecting this line to the sinus floor to compare the fluid level preoperatively and postoperatively using Galileos software (Galileos Comfort Plus-Sirona 3D).

\section{RESULTS}

The current study comprised twenty patients with oro-antral fistula (twelve males and eight females) who were treated in an outpatient clinic at the Oral and Maxillofacial Department, Faculty of Dentistry, Alexandria University, using the Caldwell-Luc method. The patients were divided 
into two groups at random. Only one case from group $\mathrm{B}$ has been excluded from the study at 3 months postoperatively due to persistent infection, and this excluded case didn't affect our results as the sample from the beginning of the study was calculated in a way to compensate for the attrition of the sample throughout the follow-up intervals.

\section{Preoperative data:}

In group $\mathrm{A}$, the surgicel soaked in herbal haemostatic agent and packed in the diseased sinus before the closure of the oro-antral fistula with buccal advanced flap and/or palatal pedicle flap through Caldwell-Luc approach. This group included ten patients, seven males and three females, their age ranged between twenty seven to fifty years old with mean value $40.1 \pm 7.57$. While in group B, surgicel soaked in PRP was used to assist in closure the oro-antral fistula with buccal advanced flap and/or palatal pedicle flap through Caldwell-Luc approach. It included also ten patients, five males and five females, their age ranged between twenty-seven to fifty years old with mean value 38.29 \pm 9.72 .

All patients gave history of previous maxillary extraction, with eleven cases of upper first molar extraction, five cases of second upper molar extraction, two cases of upper second premolar extraction, and two cases of upper third molar extraction. With the exception of four cases where the fistula had been present for more than two years, all cases had a history of extraction ranging from one month to one year.

During extraoral examination all patients complained of tenderness at the cheek area, while only eight patients suffered from submandibular lymph node swelling. Intraoral examination revealed that all the twenty patients had obvious OAF and eleven of them had postnasal discharge. CBCT showed that ten patients suffered from polypoids in the affected maxillary sinus within the two groups and only four cases had remaining roots within the sinus in the two groups.

\section{Postoperative data}

\section{I- Clinical follow-up}

Clinical evaluations were performed immediate postoperatively, at three days, one week later, two weeks later, one month, and three months after surgery

\section{Pain}

Visual analog scale was used to assess pain. In both groups patients suffered from severe pain immediate postoperatively before taking any pain killer which then decreased throughout the followup period.

These results were statically significant in each group individually, but there were no statistically significant difference between the two groups when compared together. (Table 1, Fig. 4)

\section{Swelling}

The results show statistically significant difference in each group distinctly. Also, by comparing the two groups, a statistically significant difference was observed only after three days postoperatively. (Table 2, Fig. 5).

\section{Bleeding}

In the group A, non of the cases had postoperative bleeding from the nostril, but in group B, seven patients had no bleeding and only three patients had immediate postoperative bleeding from the nostril.

After one week, non of the cases in group A showed bleeding, whereas one case in group B had bleeding from the nostril as clotted blood. Throughout the late follow-up periods for both groups, no bleeding was seen.

\section{Infection}

There were no cases of infection or pus formation at the site of OAF in the group A. Pus was found in one instance in group B after two weeks, and this case was removed from the sample and had to have another procedure later. 
TABLE (1): Comparison between the two studied groups according to pain

\begin{tabular}{|c|c|c|c|c|c|c|}
\hline & \multicolumn{6}{|c|}{ Pain } \\
\hline & Immediate & 3 days & 1 weeks & 2 weeks & 1 month & 3 months \\
\hline Group A & $(\mathbf{n}=10)$ & $(\mathrm{n}=10)$ & $(\mathbf{n}=10)$ & $(\mathrm{n}=10)$ & $(\mathrm{n}=10)$ & $(\mathrm{n}=10)$ \\
\hline Min. - Max. & $7.0-8.0$ & $4.0-7.0$ & $1.0-3.0$ & $1.0-2.0$ & $0.0-1.0$ & $0.0-1.0$ \\
\hline Mean \pm SD & $7.43 \pm 0.53$ & $5.29 \pm 1.11$ & $2.29 \pm 0.76$ & $1.57 \pm 0.53$ & $0.29 \pm 0.49$ & $0.14 \pm 0.38$ \\
\hline Median & 7.0 & 5.0 & 2.0 & 2.0 & 0.0 & 0.0 \\
\hline $\mathbf{P}$ & & $0.017^{*}$ & $0.011^{*}$ & $0.016^{*}$ & $0.016^{*}$ & $0.014^{*}$ \\
\hline Group B & $(\mathbf{n}=10)$ & $(\mathrm{n}=10)$ & $(\mathbf{n}=10)$ & $(\mathbf{n}=9)$ & $(\mathrm{n}=9)$ & $(\mathbf{n}=9)$ \\
\hline Min. - Max. & $6.0-8.0$ & $4.0-6.0$ & $2.0-3.0$ & $0.0-3.0$ & $0.0-2.0$ & $0.0-2.0$ \\
\hline Mean \pm SD & $7.14 \pm 0.69$ & $5.14 \pm 0.69$ & $2.57 \pm 0.53$ & $1.43 \pm 0.98$ & $0.50 \pm 0.84$ & $0.33 \pm 0.82$ \\
\hline Median & 7.0 & 5.0 & 3.0 & 1.0 & 0.0 & 0.0 \\
\hline $\mathbf{P}$ & & $0.026^{*}$ & $0.014^{*}$ & $0.016^{*}$ & $0.027^{*}$ & $0.023^{*}$ \\
\hline $\mathbf{Z}(\mathbf{p})$ & $0.800(0.424)$ & $0.203(0.839)$ & $0.714(0.475)$ & $0.417(0.677)$ & $0.352(0.725)$ & $0.227(0.820)$ \\
\hline
\end{tabular}

\section{Z: Z for Mann Whitney test for comparing between cases and control group}

p: $p$ value for Wilcoxon signed ranks test for comparing between immediate with each other stages

*: Statistically significant at $p \leq 0.05$

TABLE (2): Comparison between the two studied groups according to swelling

\begin{tabular}{|c|c|c|c|c|c|c|}
\hline & \multicolumn{6}{|c|}{ Swelling } \\
\hline & Immediate & 3 days & 1 weeks & 2 weeks & 1 month & 3 months \\
\hline Group A & $(\mathrm{n}=10)$ & $(\mathrm{n}=10)$ & $(\mathrm{n}=10)$ & $(\mathrm{n}=10)$ & $(\mathrm{n}=10)$ & $(\mathrm{n}=10)$ \\
\hline Min. - Max. & $9.0-15.0$ & $25.0-37.0$ & $8.0-14.0$ & $1.0-5.0$ & $0.0-1.0$ & $0.0-1.0$ \\
\hline Mean \pm SD & $11.71 \pm 2.21$ & $32.43 \pm 3.82$ & $10.29 \pm 2.21$ & $2.71 \pm 1.38$ & $0.29 \pm 0.49$ & $0.14 \pm 0.38$ \\
\hline Median & 12.0 & 33.0 & 10.0 & 2.0 & 0.0 & 0.0 \\
\hline $\mathbf{P}$ & & $0.018^{*}$ & $0.041^{*}$ & $0.016^{*}$ & $0.018^{*}$ & $0.018^{*}$ \\
\hline Group B & $(\mathbf{n}=10)$ & $(\mathbf{n}=10)$ & $(\mathrm{n}=10)$ & $(\mathbf{n}=9)$ & $(\mathbf{n}=9)$ & $(\mathbf{n}=9)$ \\
\hline Min. - Max. & $10.0-17.0$ & $33.0-42.0$ & $10.0-16.0$ & $2.0-8.0$ & $0.0-1.0$ & \\
\hline Mean \pm SD & $12.71 \pm 2.56$ & $37.43 \pm 3.10$ & $12.5 \pm 2.44$ & $3.71 \pm 2.14$ & $0.33 \pm 0.52$ & 0.0 \\
\hline Median & 13.0 & 37.0 & 12.0 & 3.0 & 0.0 & \\
\hline $\mathbf{P}$ & & $0.017^{*}$ & 0.739 & $0.018^{*}$ & $0.027^{*}$ & $0.027^{*}$ \\
\hline $\mathbf{Z}(\mathbf{p})$ & $0.715(0.475)$ & $2.308\left(0.021^{*}\right)$ & $1.676(0.094)$ & $0.993(0.321)$ & $0.178(0.859)$ & $0.926(0.355)$ \\
\hline
\end{tabular}

Z: Z for Mann Whitney test for comparing between cases and control group

p: $p$ value for Wilcoxon signed ranks test for comparing between immediate with each other stages

*: Statistically significant at $p \leq 0.05$ 


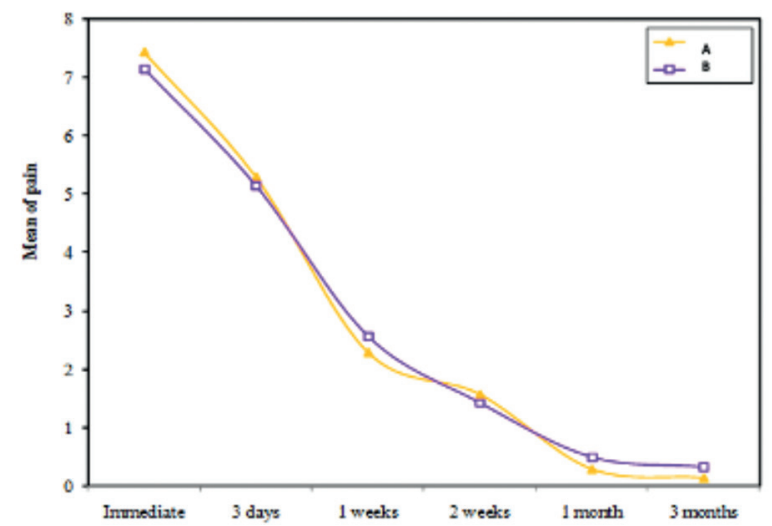

Fig. (4): Line chart graph showing comparison between the two studied groups according to pain

\section{II.Microbiological follow-up}

According to a swab taken intraoperatively directly from the maxillary sinus and postoperatively after one week from the posterior wall of the pharynx. The following was observed; In group A, four patients had Staphylococcus bacteria, three patients had streptococcus bacteria, and three patients had negative growth intraoperatively, while all patients had negative growth postoperatively. While, in group B, four patients had Staphylococcus bacteria and six patients had negative growth intraoperatively. Six patients had zero growth after one week, two had staphylococcus bacteria, and four had streptococcus and staphylococcus bacteria, which required antibiotic treatment based on the culture and sensitivity test.

\section{Radiographic follow-up}

\section{Fluid level}

After measuring the fluid level at the site of oro-antral fistula the mean value of the fluid level preoperatively was $10.86 \mathrm{~mm} \pm 6.01$ in group $\mathrm{A}$, and $10.29 \mathrm{~mm} \pm 5.77$ in group B. Then it decreased significantly after three monthsfor both groups with the mean value $2.57 \mathrm{~mm} \pm 3.36$ in group $\mathrm{A}$, and $5.67 \mathrm{~mm} \pm 4.55$ in group B. (Table 3 ). The difference

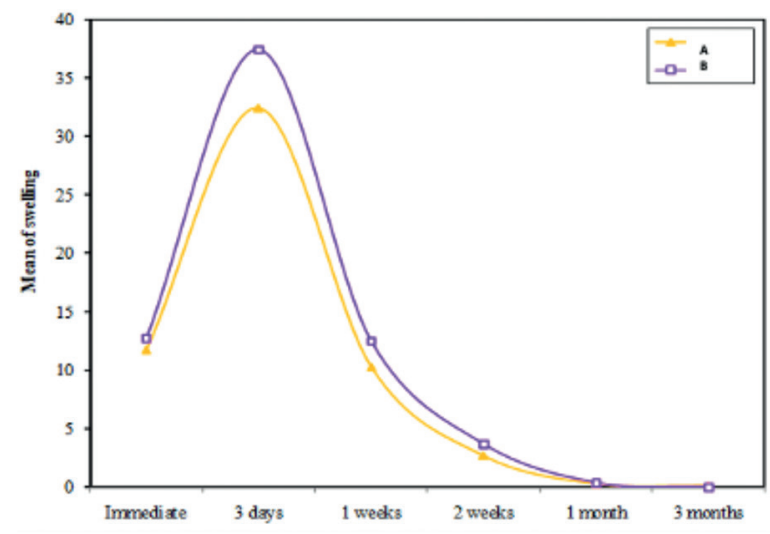

Fig. (5): Line chart graph showing comparison between the two studied groups according tomean of swelling

between the 2 groups was statistically insignificant.

TABLE (3): Comparison between the two studied groups according to Fluid level at the site of OAF by $\mathrm{mm}$

\begin{tabular}{|c|c|c|c|}
\hline & \multicolumn{2}{|c|}{ Fluid level } & \multirow{2}{*}{$\mathbf{p}$} \\
\hline & Pre & 3months & \\
\hline Group A (mm) & $(\mathrm{n}=10)$ & $(\mathrm{n}=10)$ & \\
\hline Min. - Max. & $5.0-20.0$ & $0.0-10.0$ & \multirow{3}{*}{$0.018^{*}$} \\
\hline Mean \pm SD & $10.86 \pm 6.01$ & $2.57 \pm 3.36$ & \\
\hline Median & 8.0 & 2.0 & \\
\hline Group B (mm) & $(\mathrm{n}=10)$ & $(\mathbf{n}=9)$ & \\
\hline Min. - Max. & $3.0-17.0$ & $1.0-14.0$ & \multirow{3}{*}{$0.027^{*}$} \\
\hline Mean \pm SD & $10.29 \pm 5.77$ & $5.67 \pm 4.55$ & \\
\hline Median & 10.0 & 4.50 & \\
\hline $\mathbf{Z}(\mathbf{p})$ & $0.448(0.654)$ & $1.733(0.083)$ & \\
\hline
\end{tabular}

Z: Z for Mann Whitney test for comparing between cases and control group

p: p value for Wilcoxon signed ranks test for comparing between pre and 3 months

*: Statistically significant at $p \leq 0.05$ 


\section{DISCUSSION}

This randomized clinical trial aimed to compare the use of a herbal haemostatic agent (Thymus vulgaris, Glycyrrhizaglabra, Vitisvinifera, Alpiniaoffcinarum, and Urticadioica) to plasma rich protein (PRP) in an established oro-antral fistula (OAF) after the Caldwell-Luc surgery.

Patients with well-established OAF > $5 \mathrm{~mm}$ diameter requiring management through a CaldwellLuc approach were included in this study. Similarly, Khandelwal $\mathrm{P}$ and Hajira $\mathrm{N}$, identified that quick care is necessitated in communications larger than $2 \mathrm{~mm}$ and should be treated as soon as possible to avoid sinusitis and other problems that cause patient discomfort. ${ }^{(15)}$

Several studies have found that the extractions of the first and second molars are the most common causes of oro-antral fistula. ${ }^{(16,17)}$ This concurs with our study in which most of the cases were due to first and second molars except four cases of second premolars and third molars.

In our study twelve males and eight females with age ranging from twenty seven to fifty years old. the occurrence of oro-antral fistula was in the fifth decade (57\%), which accorded with Punwutikorn $\mathrm{J}^{(18)}$, who stated that elderly patients had higher incidences of oro-antral fistula following simple extraction. Conversely, our results disagreed with Haggag et al and El-Ashrafy et al who declared higher incidence of oro-antral fistula in the third decade. ${ }^{(19,20)}$ Similarly, in agreement with our findings, Yilmaz et al, mentioned that fistulas occurrence was more common in males than females, this was attributed to more traumatic teeth extraction in males. ${ }^{(21)}$

In our study, the incidence of oro-antral fistula was found to have similar distribution on both sides, which differs with Seigneur M et al, who discovered that the roots were moved into the left antrum more frequently than the right antrum. ${ }^{(22)}$

The current study showed that the herbal hemostatic agent and the PRP did not play a role in reducing pain sensation, as both groups experienced maximum pain immediately after surgery which then subsided over time. This contradicts Tasdelen et al, who declared in his study that the antiinfective behavior of the herbal hemostatic agent had been shown, and thus less pain sensation. ${ }^{(11)}$

In terms of postoperative swelling, the current study found that when comparing the two groups on the third day, the swelling was significantly higher in group B than group A. However, it subsided spontaneously in the subsequent follow-up periods in both groups. This was consistent with Sezik et al, who stated that postoperative edema reached its peak at the first week after surgery. ${ }^{(23)}$ In addition, these findings were found to be approving with a study by Edrev $\mathrm{S}$ and Peev S, who stated that the use of PRP favorably reduced pain and edema pain scores between the first and seventh day in patients with radicular cysts that had been surgically removed. ${ }^{(24)}$

In terms of postoperative bleeding, the current study indicated that throughout the late followup periods for both groups, no bleeding was seen. which is consistent with Ercetin and Beyazit's findings that the herbal hemostatic substance causes a very quick creation of a protein network in plasma and serum samples. ${ }^{(6,25)}$ Also, the herbal drug allowed the erythrocytes to cluster in less than a second to develop a network. Moreover, the herbal hemostatic agents work independently of the traditional coagulation cascade leaving the individual coagulation factors unaffected. (26)

Likewise, this was in agreement with Ma et al who highlighted that PRP appears to be effective in reducing postoperative blood loss and reducing Hemoglobin drop. ${ }^{(27)}$ On the other hand, a study by Godet $G$ et al stated that PRP doesn't sufficiently reduce blood loss and explained that this may be attributed to the moderate enrichment of platelets observed with the centrifugation speed utilized in their study ${ }^{(28)}$

Radiographically, the fluid level decreased significantly after three months in both groups, yet no 
significant difference was observed between them. This indicates efficient wound healing potential of both the herbal product and the PRP. This agrees with Smith et al who concluded that autologous PRP has showed potential in stimulating and speeding up soft-tissue and bone repair. The success is due to the local distribution of an abundant range of growth factors and proteins that mimic and enhance natural wound healing and tissue repair processes. ${ }^{(29)}$

In terms of postoperative infection, this study found that the herbal hemostatic agent and PRP had a positive outcome on reducing infection and pus formation with only one case of infection in group B which was excluded from the study after two weeks. In relation to the herbal hemostatic agent, this was consistent with Shibata et al, who discovered that ingredients within this drug; Alpiniaofficinarum and Glycyrrhizaglabra have anti-inflammatory effects on wound healing. ${ }^{(30)}$

In terms of microbiology, group A showed Staphylococcus and Streptococcus colonization from the intraoperative swab and then negative growth after one week, which was consistent with Tasdelen et al and Awad et al's findings that plant extract hemostatics had antimicrobial activity against Gram +ve and Gram -ve bacteria. ${ }^{(11,31)}$ In group B, the bacteria were not completely eradicated by PRP as postoperatively, group B showed positive growth of streptococcus and staphylococcus bacteria in four patients. In our opinion, this could be owing to the elevated pathogenicity of the clinical bacterial strains in some patients.

An antimicrobial study by Hongshuai Li and Bingyun Li, stated that PRP possesses a strong in vitro antimicrobial activity against bacteria including methicillin-sensitive and methicillin-resistant Staphylococcus aureus, Group A Streptococcus, and Neisseria gonorrhoeae. However, PRP can be better used in conjunction with systemic or local antibiotic therapy, since the synergistic effect of this combination can enable greater bacterial clearance preventing infection. ${ }^{(32)}$

\section{CONCLUSION}

There were little postoperative complications with the herbal haemostatic medication and PRP. Both were also successful in lowering the amount of fluid in the maxillary sinus. The herbal haemostatic medication, on the other hand, surpassed PRP in terms of antibacterial activity. Further clinical studies comparing different herbal drugs and PRP prepared with different centrifugation speeds to improve patient outcomes are recommended.

\section{CONFLICTS OF INTEREST}

The authors have no conflicts of interest to declare

\section{REFERENCES}

1. Miloro M G, Ghali GE, Larsen PE, Waite PD. Peterson's Principles of Oral \& Maxillofacial Surgery. 2nd ed. Canada; 2004. 295-312. p.

2. Lee KC, Lee SJ. Clinical features and treatments of odontogenic sinusitis. Yonsei Med J. 2010 Nov;51(6):932-7.

3. Ogle OE. The management of oronasal fistulas in the cleft palate patient. Oral Maxillofac Surg Clin N Am. 2002 Nov 1;14(4):553-62.

4. Dergin G, Emes Y, Delilbası C, Gurler G. Management of the Oroantral Fistula. A Textbook of Advanced Oral and Maxillofacial Surgery: Volume 3. 2016 Aug 31:3367.

5. Akhlaghi F, Esmaeelinejad M, Safai P. Etiologies and treatments of odontogenic maxillary sinusitis: a systematic review. Iranian Red Crescent Medical Journal. 2015 Dec;17(12).

6. Ercetin S. Safety and Efficacy of Ankaferd Blood Stopper in Dental Surgery. Int J Hematol Oncol. 2010 Mar $1 ; 20(1): 1-5$.

7. Marx RE. Platelet-rich plasma: evidence to support its use. J Oral Maxillofac Surg Off J Am Assoc Oral Maxillofac Surg. 2004 Apr;62(4):489-96.

8. Liu Y, Kalén A, Risto O, Wahlström O. Fibroblast proliferation due to exposure to a platelet concentrate in vitro is pH dependent. Wound Repair Regen Off Publ Wound Heal Soc Eur Tissue Repair Soc. 2002 Oct;10(5):336-40.

9. Rosner B. Fundamentals of biostatistics. Cengage learning; 2015 Jul 29. 
10. Universität Düsseldorf: G*Power [Internet]. [cited 2021 Sep 29]. Available from: https://www.psychologie. hhu.de/arbeitsgruppen/allgemeine-psychologie-undarbeitspsychologie/gpower

11. Tasdelen Fisgin N, Tanriverdi Cayci Y, Coban AY, Ozatli D, Tanyel E, Durupinar B, et al. Antimicrobial activity of plant extract Ankaferd Blood Stopper. Fitoterapia. 2009 Jan;80(1):48-50.

12. Nitecka-Buchta A, Walczynska-Dragon K, Kempa WM, Baron S. Platelet-Rich Plasma Intramuscular Injections - Antinociceptive Therapy in Myofascial Pain Within Masseter Muscles in Temporomandibular Disorders Patients: A Pilot Study. Front Neurol. 2019;10:250.

13. Benetello V, Sakamoto FC, Giglio M, Sakai VT, Calvo A, Modena KCS, et al. The selective and non-selective cyclooxygenase inhibitors valdecoxib and piroxicam induce the same postoperative analgesia and control of trismus and swelling after lower third molar removal. Braz J Med Biol Res Rev Bras Pesqui Médicas E Biológicas Soc Bras Biofísica Al. 2007 Sep 1;40:1133-40.

14. Morawska-Kochman M, Marycz K, Jermakow K, Nelke K, Pawlak W, Bochnia M. The presence of bacterial microcolonies on the maxillary sinus ciliary epithelium in healthy young individuals. PLoS ONE. 2017 May 2;12(5):e0176776.

15. Khandelwal $P$, Hajira N. Management of oro-antral communication and fistula: various surgical options. World journal of plastic surgery. 2017 Jan;6(1):3.

16. Parvini P, Obreja K, Sader R, Becker J, Schwarz F, Salti L. Surgical options in oroantral fistula management: a narrative review. Int J Implant Dent. 2018 Dec 27;4(1):40.

17. Shokry M. Efficiency of using platelet rich fibrin plug for closure of oroantral fistula. Egypt Dent J. 2017 Feb 1;63(2):1253-60.

18. Punwutikorn J, Waikakul A, Pairuchvej V. Clinically significant oroantral communications--a study of incidence and site. Int J Oral Maxillofac Surg. 1994 Feb;23(1):19-21.

19. Haggag MA, El-Dibany M, Shawky N, Mounir M. The use of growth factors (PRP, PPP) as a biological barrier for closure of Oro-antral fistula. [Master Thesis Oral and Maxillofacial Department]. Alexandria Uni.; 2007

20. El-Ashrafy BM, El-Dibany M, Ragaa H. oroantral fistula closure with rigid resorbable membrane versus conventional flap [Master Thesis Oral and Maxillofacial Department]. Alexandria Uni.; 2009.
21. Yilmaz T, Suslu A, Gursel B. Treatment of oroantral fistula: Experience with 27 cases. Am J Otolaryngol. 2003 Jul 1;24:221-3.

22. Seigneur M, Cloitre A, Malard O, Lesclous P. Teeth roots displacement in the maxillary sinus: characteristics and management. Journal of Oral Medicine and Oral Surgery. 2020;26(3):34.

23. Sezik E, Yeşillada E, Tabata M, Honda G, Takaishi Y, Fujita T, et al. Traditional medicine in Turkey VIII. Folk medicine in east anatolia; Erzurum, Erzíncan, Ağri, Kars, Iğdir provinces. Econ Bot. 1997 Jul 1;51(3):195-211.

24. Edrev S, Peev S. Effect on pain and facial edema of platelet-rich plasma in removed radicular cysts. Varna Med Forum. 2020 Jul 21;9:163.

25. Beyazit Y, Kurt M, Kekilli M, Goker H, Haznedaroglu IC. Evaluation of hemostatic effects of Ankaferd as an alternative medicine. Altern Med Rev J Clin Ther. 2010 Dec;15(4):329-36.

26. Goker H, Haznedaroglu IC, Ercetin S, Kirazli S, Akman U, Ozturk Y, et al. Haemostatic actions of the folkloric medicinal plant extract Ankaferd Blood Stopper. J Int Med Res. 2008 Feb;36(1):163-70.

27. Ma J, Sun J, Guo W, Li Z, Wang B, Wang W. The effect of platelet-rich plasma on reducing blood loss after total knee arthroplasty: A systematic review and meta-analysis. Medicine. 2017 Jun;96(26).

28. Godet G, Canessa R, Arock M, Baron JF, Kieffer E, Viars P. [Effects of platelet-rich plasma on hemostasis and transfusion requirement in vascular surgery]. Ann Fr Anesth Reanim. 1995;14(3):265-70.

29. Smith RG, Campbell MS. Platelet-Rich Plasma: Properties and Clinical Applications. 2007;2(2):6.

30. Shibata S. Antitumor-promoting and anti-inflammatory activities of licorice pirinciples and their modified compounds, in Food Phytochemicals II: Teas, Spices, and Herbs. American Chemical Society; 1994a.

31. Awad E, Khalil AF, Elashwah A. Clinical evaluation of the effect of Ankaferd Blood Stopper on the postoperative sequelae after surgical extraction of impacted mandibular third molars. [Master Thesis Oral and Maxillofacial Department,]. Alexandria Uni.; 2012.

32. Li H, Li B. PRP as a new approach to prevent infection: preparation and in vitro antimicrobial properties of PRP. J Vis Exp JoVE. 2013 Apr 9;(74). 